\title{
INVESTIGATING NATURAL TRANSITION METAL COORDINATION ANTHOCYANIN COMPLEX IN JAVA PLUM (Syzygium cumini) FRUIT AS FREE RADICAL SCAVENGING
}

\author{
A.A.S.A. Sukmaningsih ${ }^{1,3}$, S. Permana ${ }^{1}$, D.J.D.H. Santjojo ${ }^{2}$, \\ A.Y.P. Wardoyo ${ }^{2}$ and S.B. Sumitro ${ }^{1 *}$ \\ ${ }^{1}$ Biology Department, Faculty of Mathematics and Natural Sciences, Brawijaya University, \\ Malang, East Java, Indonesia \\ ${ }^{2}$ Physics Department, Faculty of Mathematics and Natural Sciences, Brawijaya University, \\ Malang, East Java, Indonesia \\ ${ }^{3}$ Biology Department, Faculty of Mathematics and Natural Sciences, Udayana University, \\ Badung, Bali, Indonesia \\ *E-mail: sutiman@ub.ac.id
}

\begin{abstract}
This research aimed to prove the existing natural transition of Metal Coordination Anthocyanin complex (MAC) from the freeze-dried of Java plum (Syzygium cumini) fruit and its role as free radical scavenging. The Liquid Chromatography-Mass Spectrometry (LCMS) analysis showed the presence of anthocyanin in the fruit, while transition metals of $\mathrm{Fe}, \mathrm{Cu}$, and $\mathrm{Ni}$ were also found as detected by X-Ray Fluorescence (XRF). The Fourier Transform Infrared Spectroscopy (FTIR) spectra revealed the interaction of organic functional groups with transition metals. These facts were supported by X-Ray Powder Diffraction (XRD) and polarizing microscope images which displayed both amorphous and crystallite microstructures related to organic and bioinorganic content in the fruit. The analysis of complex compound indicated the transition metal as coordinator atom and a cyanidin acts as a chelator among anthocyanins existing in the fruit. The paramagnetic property of MAC in the fruit as a free radical scavenger was demonstrated by the reduction of 1, 1-diphenyl-2-picrylhydrazyl (DPPH) radical intensity in the Electron Spin Resonance (ESR) spectrum. These findings suggested that S.cumini fruit contains naturally existing MAC.

Keywords: Free radical scavenger, complex compound, metal elements, anthocyanin, $S$ cumini fruit

(C) RASĀYAN. All rights reserved
\end{abstract}

\section{INTRODUCTION}

The role of free radicals in a living system is important to support normal biological functions. However, if the number of the free radicals exceed the antioxidant defense system, various deleterious biological processes can occur. Complex molecules such as hemoglobin and Superoxide dismutase (SOD) play an important role in scavenging free radicals in life. ${ }^{1,2}$ This compound is formed by bonding between metal ions and a ligand. The metal as central atom while protein, flavonoid, or other molecules as a ligand. The metals have an obvious propensity to interact with molecular organic ligands to form various structures of complex bioinorganic compounds. Chemical components naturally form composite structures. These structures form a molecular complex with its capacity for utilizing physical and chemical properties It has been reported that flavonoid or anthocyanin, such as cyanidin 3 glucoside, and catechin ${ }^{4}$ can bind metals. ${ }^{3,4}$ The transition metal and anthocyanin complexes (MAC) have a metal atom as a central coordinator which is able to perform electrons transfer and function in scavenging free radicals ${ }^{5}$. Free radicals can be used as the source of energy in the normal life, but their overwhelming production must be controlled. A considerable amount of free radicals may result in oxidative stress and damage to lipid, protein, and $\mathrm{DNA}^{6,7}$. Thus, the MAC can help control the overwhelming production of free radicals.

Rasayan J. Chem., 11(3), 1193-1203(2018)

http://dx.doi.org/10.31788/RJC.2018.1133047

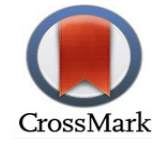


Free radicals are atoms or molecules containing at least one unpaired electrons in their outer orbitals ${ }^{8}$. The unpaired electrons result in paramagnetic properties which urge to transform the molecule into a stable form. Electrons in every orbital must be paired and these paired electrons must rotate on the axis of opposite direction ${ }^{9}$. This form refers to a stable form of an atom which has diamagnetic properties. Anthocyanin which possesses two aromatic rings and more than one hydroxyl or carboxyl groups is able to form MAC with metal ions which function as free radical scavengers. The MAC activity is similar to Superoxide dismutase (SOD) an enzyme of an endogenous antioxidant system ${ }^{10}$. The radical scavenging potentials of metal flavonoid complexes are significantly higher than those of single flavonoids ${ }^{11}$.

Java plum (S. cumini) fruit belongs to the family Myrtaceae. The colors of the fruit are red, purple ${ }^{12}$, or blue-black indicating the presence of flavonoid called anthocyanin. Each colorization depends on $\mathrm{pH}$, interactions with metal ions such as $\mathrm{Al}^{3+}, \mathrm{Fe}^{3+}, \mathrm{Mg}^{2+}$ and co-pigmentation with flavones ${ }^{13}$, flavonols and hydroxycinnamic acids. ${ }^{14}$ It is possible for this fruit to overcome an excessive number of free radicals. Java plum (S. cumini) fruit has been used for anti-allergic and anti-edematogenic ${ }^{15}$, whilst its leaves perform as the anti-bacterium activity of Salmonella typhimurium, Staphylococcus aureus, and Enterococcus faecalis ${ }^{16}$. The fruit is also used as anti-hyperglycemic and anti-dyslipidemic properties in diabetic ${ }^{17}$.

The present study aimed to prove the nature of java plum that contains bioinorganic anthocyanin metal complexes and function as a free radical scavenger. This finding is crucial since the free radical scavenger activity of bioinorganic metal anthocyanin complex compound has been known to be more effective than single compounds. A chain reaction may begin when molecules within cells lose an electron to an oxidizing compound; the molecule then now transforms into an oxidizer. It seeks for another electron and may take it from another weaker molecule, then try to oxidize it as a result. However, anthocyanin metal complexes enable to either donate or accept an electron by changing their magnetic character from paramagnetic to diamagnetic or vice versa. Thus they will not become oxidant itself.

This research was conducted through an analysis of complex compounds of transition metals, anthocyanin identification, crystal investigation, and analysis of MAC function as radical scavengers. Elemental contents were assessed by using an XRF Spectrometry. Observations on anthocyanin molecules in fruit were conducted by using LCMS. FTIR was used to confirm the presence of the transition metal and organic compound interaction vibration assignment. A morphological observation using a polarizing microscope and XRD analysis proved the existence and properties of a crystal. Radical scavenger activity and paramagnetic properties of the fruit were characterized by using an ESR.

\section{EXPERIMENTAL}

Equipment used in this research were : freeze dryer, common glassware, screen filter with 200 mesh, centrifuge, a rotary evaporator, membrane filter (PTFE) $0.2 \mu \mathrm{m}$, X-ray Fluorescence PAN-alytical's MiniPal 4 type (Almelo, the Netherlands), UHPLC from Thermo Scientific ACCELLA (type 1250), Hypersil Gold column (50 mm x $2.1 \mathrm{~mm}$ x $1.9 \mu \mathrm{m}$ ), MS/MS triple Q (quadrupole) mass spectrometer (TSQ Quantum Access MAX from Thermo Finnigan), electrospray ionization (ESI), TSQ tune software, XRD (Xpert MPD), A polarizing microscope (Nikon, Japan) and JEOL electron spin resonance spectrometer (JES - RE1X, Tokyo, JAPAN). The materials used were: S. cumini fruit freeze dried, 1,1-diphenyl-2picrylhydrazyl (DPPH), methanol, formic acid, aquabidest, acetonitrile, and $\mathrm{KBr}$ (Potassium bromide).

\section{Fruit Preparation}

Java plum (S. cumini) fruit was collected from Denpasar, Bali, Indonesia. A ripe, fresh, and blue fruit was used in this research. The fruit was washed and separated from its seed. One hundred grams of the fruit was dried by a freeze-drying process for $72 \mathrm{~h}$. As a result, $13.5 \mathrm{~g}$ of the fruit was obtained. It was ground for ten minutes to obtain a sample of powder and filtered by using a screen filter with 200 mesh. The sample was then stored at the temperature of $4^{\circ} \mathrm{C}$.

\section{Complex Compound Identification: XRF, LC/MS, FTIR, XRD analyses and Polarization Microscopy XRF Analysis}

The element of java plump (S. cumini) fruit was identified by an XRF (X-ray fluorescence). The analysis was conducted by measuring the wavelength and intensity of the X-ray photons emitted from the sample. 
The pellets of the sample were loaded into holder cups. X-ray Fluorescence analysis was conducted by PAN-alytical's MiniPal 4 type (Almelo, the Netherlands).

\section{LC/MS Analysis}

Java plum extract $0.5 \mathrm{~g}$ was put into a centrifuge tube and added with methanol $10 \mathrm{~mL}$ which contained $2 \%$ of formic acid. The solution was shaken for one minute and after that sonicated for 30 minutes at $25^{\circ} \mathrm{C}$. Samples were centrifuged for 10 minutes at $10.000 \mathrm{rpm}$. The supernatants were dried with a rotary evaporator at $<40^{\circ} \mathrm{C}$. The residues were reconstituted with $10 \mathrm{ml}$ of water which contained $2 \%$ formic acid and $10 \%$ of methanol. Prior to the LC-MS/MS analysis, samples were filtered with $0.2 \mu$ membrane filter (PTFE)

The anthocyanin compounds were qualitatively identified using LC-MS equipment according to the previous study A UHPLC from Thermo Scientific ACCELLA (type 1250) was used. The instrument is equipped with a Hypersil Gold column $(50 \mathrm{~mm}$ x $2.1 \mathrm{~mm} \times 1.9 \mu \mathrm{m})$. The eluent A consisted of $0.1 \%$ formic acid in aquabidest. The eluent $\mathrm{B}$ consisted of $0.1 \%$ formic acid in acetonitrile. A linear gradient at a rate of $300 \mu \mathrm{L} /$ minute had the following mobile phase settings: $0-1.0$ minute of $85 \% \mathrm{~A}, 1-3.5$ minutes of $15 \%$ A, 3.5-5.40 minutes of $85 \% \mathrm{~B}, 5.40-5.50$ minutes of $15 \% \mathrm{~B}$. The use of MS/MS triple Q (quadrupole) mass spectrometer (TSQ Quantum Access MAX from Thermo Finnigan) with an electrospray ionization (ESI) source was controlled by TSQ tune software which was operated in the positive mode. The conditions of ESI ionization were as follows: spray voltage $3 \mathrm{kV}$, evaporation temperature at $270^{\circ} \mathrm{C}$, capillaries temperature at $300^{\circ} \mathrm{C}$, nitrogen as sheath gas pressure at 40 psi and AUX gas pressure at 10 psi with argon gas. ${ }^{18}$ The qualitative identification result of anthocyanins by the Selected Reaction Monitoring (SRM) mode of LC/MS was shown in Table-1 as a previous study. ${ }^{19-21}$

\section{FTIR Analysis}

IR spectra in the java plum (S. cumini) fruit was recorded by using FTIR spectrophotometer (Shimadzu, Japan). The sample was mixed with $1 \mathrm{mg} / 100 \mathrm{mg} \mathrm{KBr}$ (Potassium bromide). Either organic or inorganic compounds which possess a covalent bond will absorb various frequencies of electromagnetic radiation at a particular wavelength $((\lambda) 0.5-1000 \mu \mathrm{m})$. The most useful domain to help recognize the structure of a compound is the one at the $1-25 \mu \mathrm{m}$ frequency or at a wave number between 10.000 and $400 \mathrm{~cm}^{-1}$.

\section{Crystal Analysis}

Crystal characterization was performed by an XRD (Xpert MPD). The sample was scanned by using copper $(\mathrm{Cu}) . \mathrm{K} \alpha$ radiation with a wavelength of $1.54056 \AA$ at $20 \mathrm{~mA}, 36 \mathrm{kV}$. The scanning region of the angle at $2 \theta$ was from $5^{\circ}$ to $60^{\circ}$ (step size 0.01 , time per step $10 \mathrm{~s}$, a divergence slit width (DS) of $0.25^{\circ}$, a receiving slit width (RS) of $12.75 \mathrm{~mm}$. The sample was equilibrated at $50^{\circ}$ prior to analysis. The result of this process showed X-ray diffraction which was subsequently recorded as the diffraction patterns. These conditions were performed according to the previously published procedure. ${ }^{22}$

A polarizing microscope (Nikon, Japan) was used to investigate the existence of crystalline in the freezedried Java plum fruit. A Nikon plastic polarizing filter was used as a polarizer and an analysis tool. Illumination was provided by a halogen lamp. The object was observed at a rectified objective (Nikon, 40 x, N.A. 0.65).

\section{Scavenging Activity and Electron Spin Resonance Measurement of Paramagnetic Properties and DPPH Radical}

The paramagnetic properties and scavenging activity of the Java plum fruit against DPPH radicals were measured by a JEOL electron spin resonance spectrometer (JES - RE1X, Tokyo, JAPAN). Each sample was measured by using these following parameters: field modulation of 1 x $1 \mathrm{mT}$; sweep time at 20s, sweep width of $1 \times 10 \mathrm{mT}$, time constant at $0.03 \mathrm{~s}$, center field on $335 \mathrm{mT}$, frequency at $9.445 \mathrm{GHz}$, microwave power of $1 \mathrm{~mW}$, temperature of $297^{\circ} \mathrm{K}$. The receiver gained 400 times. Mn metal ion was used as the standard of paramagnetic atom. ${ }^{23}$

\section{Complex Compound Identification}

\section{RESULTS AND DISCUSSION}

The result of XRF characterization showed that java plum fruit contains major elements namely $\mathrm{K}, \mathrm{Ca}, \mathrm{P}$, $\mathrm{Cu}, \mathrm{Ni}$, and $\mathrm{Fe}$. The last three elements are classified as transitional metals. Valence electron configuration 
RASĀYAN $J$. Chem.

Vol. 11 | No. 3 |1193 - 1203 | July - September | 2018

of $\mathrm{Fe}$ atom is $3 \mathrm{p}^{6} 4 \mathrm{~s}^{2} 3 \mathrm{~d}^{6}$, of $\mathrm{Ni}$ is $3 \mathrm{p}^{6} 4 \mathrm{~s}^{2} 3 \mathrm{~d}^{8}$ and of $\mathrm{Cu}$ is $3 \mathrm{p}^{6} 4 \mathrm{~s}^{2} 3 \mathrm{~d}^{9}$. The electron configurations showed that the $d$ orbital of transition metals is partially filled. The unpaired electron of these metals was able to accept a paired electron which filled orbital by coordinating bond to specific molecules or anions and forming a complex ion or complex compound. These metals such as $\mathrm{Fe}, \mathrm{Cu}$, and $\mathrm{Ni}$ which have unpaired electrons will act as the center of the atom and play a crucial role in the MAC formation.

Based on the results of the LCMS analysis, the anthocyanins were detected in the $S$. cumini fruit as seen in Figure-1. The anthocyanins compounds were identified as follows Cyanidin-3,5- $O$-diglucoside at retention time (RT) $2.74 \mathrm{~min}$, Delphinidin-3- $O$-glucoside at RT $3.01 \mathrm{~min}$, Malvidin-3,5- $O$-diglucoside at RT 3.15, Cyanidin-3-O-glucoside at RT 3.62, Peonidin-3-O-glucoside at RT 3.75, Cyanidin -3-Opentoside at RT 3.91, Pelargonidin-3- $O$-glucoside at RT 4.20, and Malvidin-3- $O$-( $t$-611- $O$-coumaroyl)glucoside, 5-O-glucoside at RT 4.34. These results were in good agreement with other works reported so far. ${ }^{19-21}$

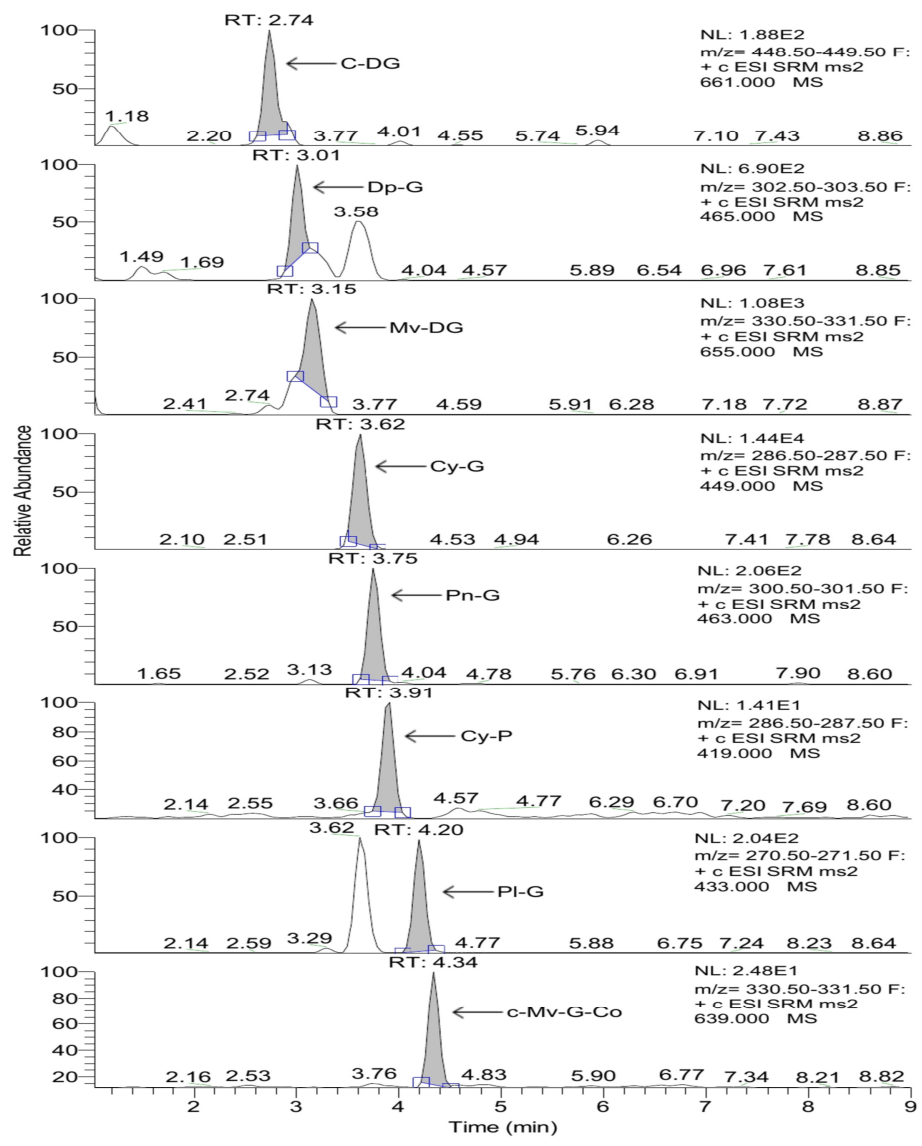

Fig.-1: Typical Chromatogram of the Anthocyanins in Java Plum as Detected by LCMS in SRM Mode

Cyanidin-3,5-O-diglucoside is a molecule with a catechol structure on the B ring when chelates transition metals and forms a complex compound. This finding is similar to the study result suggesting the chelation of $\mathrm{Fe}^{3+}$ by cathecolate-type polyphenol ${ }^{4}$. Anthocyanin is polyphenol compounds which contain 15 carbon atoms in a flavan structural backbone (C6-C3-C6). Each compound consists of two aromatic rings denoted as $\mathrm{A}$ and $\mathrm{B}$ which are linked by a heterocyclic pyrane ring (C-ring). Phenolic hydroxyl, sugar, oxygen, or methyl group are attached to the ring. It is known that the flavonoid and anthocyanin perform radical scavenging activity because the electrons are delocalized from the $\mathrm{B}$ ring $^{24}$ and the phenolic hydroxyl group of this structure. Phenolic hydroxyl can act as a source of electrons for free radicals through a mechanism of hydrogen atom donation, or through a single electron transfer ${ }^{25}$. Cyanidin can act as a chelator of various metal ions such as $\mathrm{Fe}^{2+}, \mathrm{Co}^{2+}, \mathrm{Ni}^{2+}, \mathrm{Cu}^{2+} \mathrm{Zn}^{2+}{ }^{26}$. There are sites in each flavonoid and anthocyanin molecule which can interact with metal ions such as the 3',4'-dihydroxy group on the B ring ${ }^{27}$, the 3-hydroxy or 5- 
RASĀYAN J. Chem.

Vol. 11 | No. 3 |1193 - 1203 | July - September | 2018

hydroxy ${ }^{28}$, and the 4-carbonyl groups in the $\mathrm{C}$ ring $^{26}$. Due to the presence of this structure, Cyanidin 3,5 diglucoside easily chelates metals and creates MAC.

The FTIR spectra (Fig.-2) indicated the bonding between transition metals and organic compounds found in Java plum (S. cumini) fruit. It was detected by the absorption of vibrations at wave number $900-450$ $\mathrm{cm}^{-1}$. The absorption varied and corresponded to the interaction of the transition metals with different organic compounds. The absorption of $\mathrm{Cu}-\mathrm{O}$ was detected at $765-735 \mathrm{~cm}^{-1}$, whereas $\mathrm{Fe}-\mathrm{O}$ was confirmed by wavenumber of $625-490 \mathrm{~cm}^{-1} 29$. Additionally, the absorption band at $571.81 \mathrm{~cm}^{-1}$ was also identified as $\mathrm{Fe}-\mathrm{O}^{30}$.

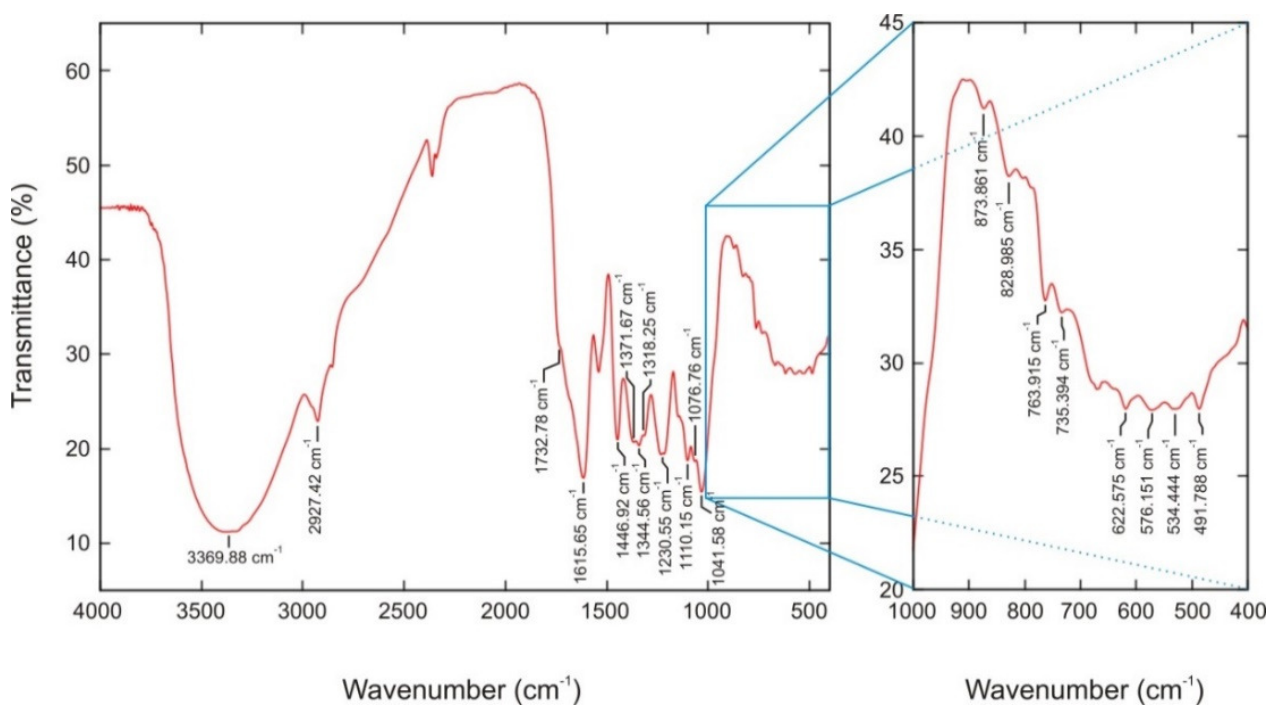

Fig.-2: FTIR Spectra showed the Lower Wave Number of the Peak Related to the Metal Interaction of Complex Compound in $S$. cumini Fruit

The one predicted the structure of transition metal and organic compound interaction with $\mathrm{Fe}^{2+}$ as the central atom and cyanidin as ligands in java plum (S. cumini) fruit (Fig.-3) was similar to the one modeled in the previous study ${ }^{28}$.

Metal ions which prefer octahedral geometry, $\mathrm{Fe}^{2+}$ and $\mathrm{Fe}^{3+}$ for instance, can match up to three catecholate or gallate groups. Since polyphenol ligands strongly stabilize $\mathrm{Fe}^{3+}$ over $\mathrm{Fe}^{2+}$, catecholate and gallate complexes of $\mathrm{Fe}^{2+}$ are promptly oxidized in the $\mathrm{O}_{2}$ occurrence to provide $\mathrm{Fe}^{3+}$-polyphenol complexes. Chelation of $\mathrm{Fe}^{2+}$ by polyphenols results in electron transfer reaction in the oxygen presence, generating $\mathrm{Fe}^{3+}$-polyphenol complex and developing very stable complexes. Thus, this complex exists in solution. Physically, transtition metal $\mathrm{Fe}^{2+}$ and $\mathrm{Fe}^{3+}$, in this case, are part of the scavenger mechanism. The change of magnetic properties from paramagnetic one becomes a complex diamagnetic compound when losing or obtaining electrons from free radicals.

The freeze-dried java plum fruit powder process indicating a chemical reaction did not exist. However, there was a possibility that the position of atoms nearby formed an order of crystal $^{31}$. Crystal is a material which has an organized three-dimension regular pattern with a directional atomic bonding and a tight order. XRD pattern of the java plum (S. cumini) fruit is displayed in Fig.-4. The sample showed a wide peak representing the existence of amorphous structures and a number of sharp peaks representing the crystal structures. This finding was in line with the previous research. It was reported that XRD spectra of freezedried grape juice powder contain amorphous and crystal structures ${ }^{32}$. The existence of a crystal in the fruit was in accordance with observation results using a polarizing microscope (Fig.-5).

The amorphous structure caused the fruit contains both organic and bioinorganic components. The composition and structure of biological materials contained both organic and bioinorganic components form a complex structure. This complex structure is a molecular system composed of a high number of atoms which contain covalent, ionic, and weak bonds coexisting together. They are arranged at the nano, micro, and meso levels. The organic materials include $\mathrm{C}, \mathrm{H}$, and $\mathrm{O}$ based compounds of organic which constitute amorphous structures ${ }^{33}$. The bioinorganic components of the fruit are complex compounds 
containing one or more metal atoms. The results of observations conducted by using a polarizing microscope indicated that the fruit contained a crystal. However, the broad peak of XRD spectra with some weak sharp peaks showed that the microcrystal in the fruit is amorphous crystal. Transition metal contained in java plum fruit is closely related to the formation of the crystal. The anthocyanin easily chelates metals which form a bioinorganic crystal. The crystal of transitional metal such as Fe-ion as central atom and anthocyanin as ligands complexes ${ }^{34}$ has dynamic electron transfer properties which can be related to its function as a free radical scavenger.

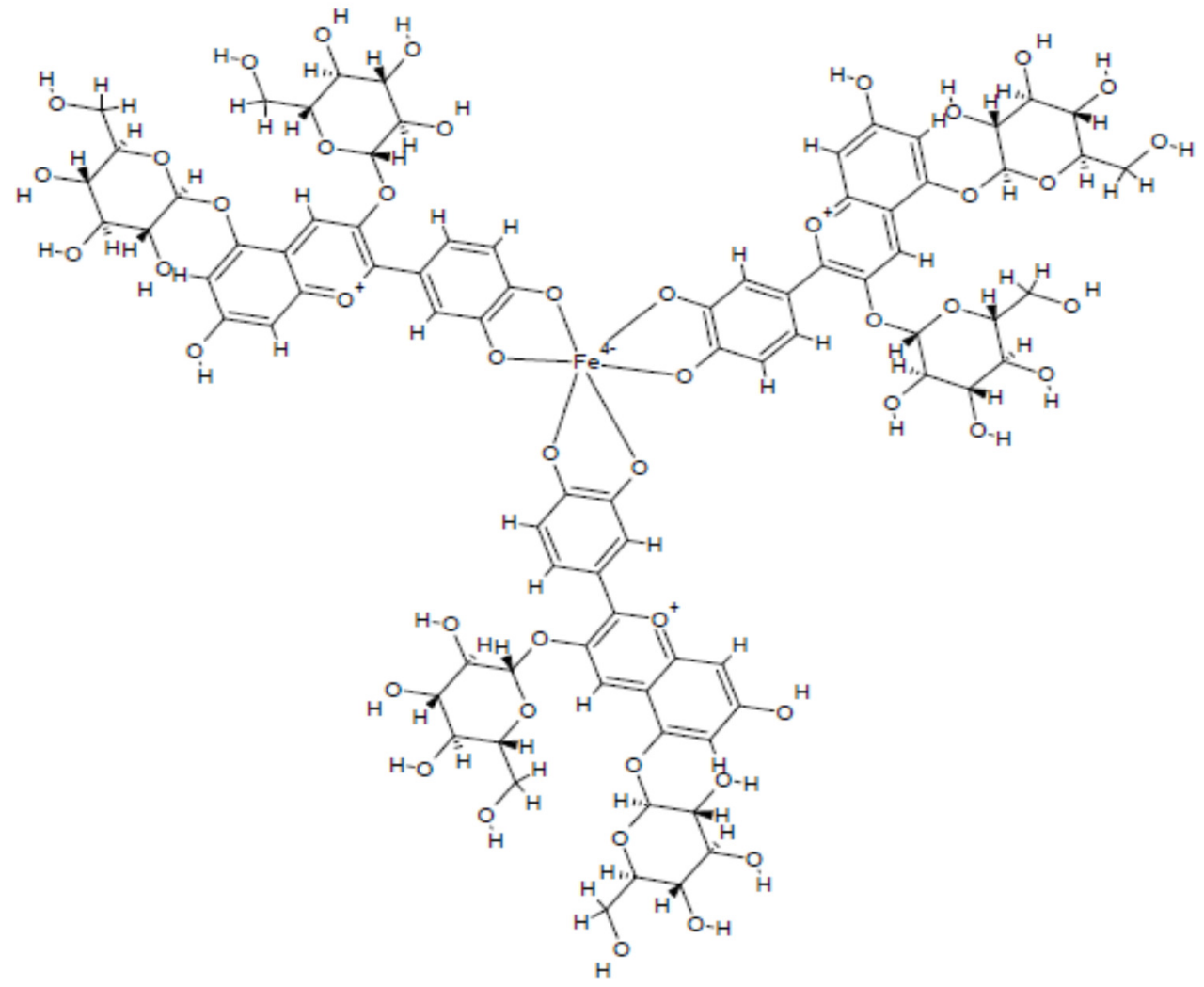

Fig.-3: The one predicted the structure of $\mathrm{Fe}^{2+}$ and cyanidin complexes were found in S. cumini fruit $\left(\mathrm{Fe}^{2+}+3 \text { (cyanidin) }\right)^{-2} \rightarrow 2 \mathrm{Fe}(\text { Cyanidin })^{-4}$

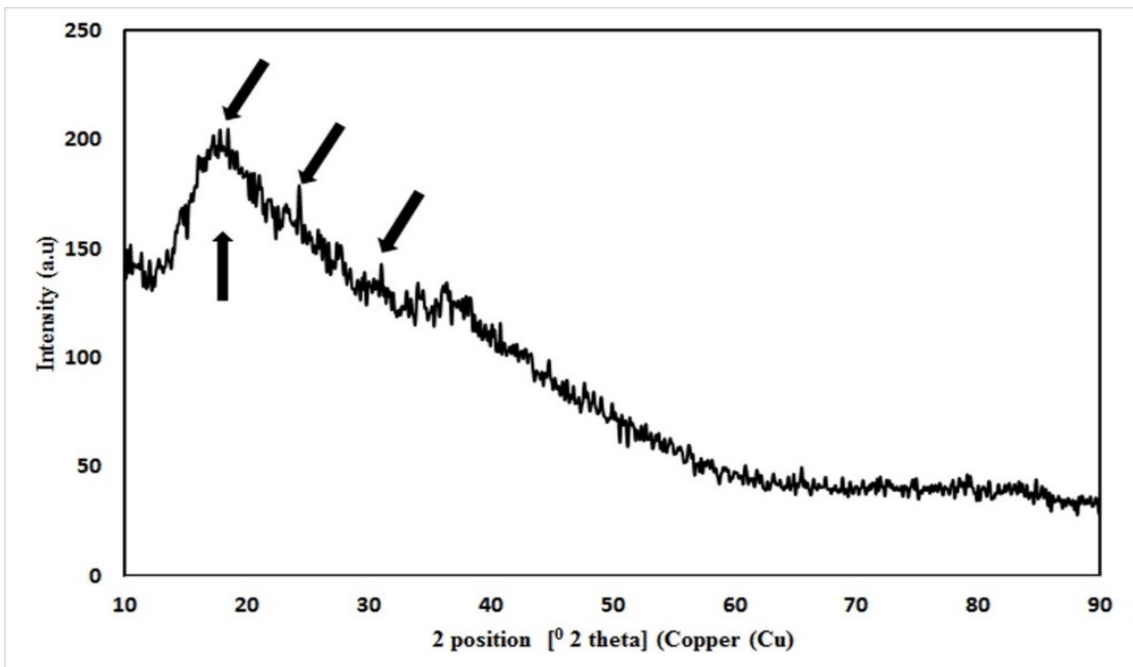

Fig.-4: The XRD Pattern of S.cumini Fruit showed Amorphous (-) and Crystallite Growth (l) 


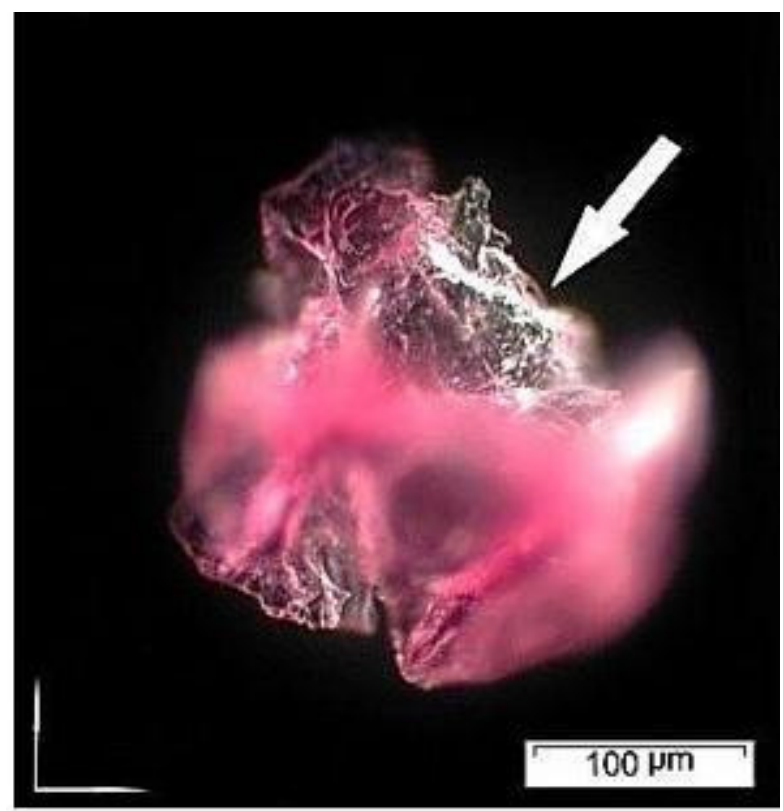

Fig.-5: The Freeze Dried S. cumini Fruit Observed From Polarization Microscope Showing A Crystal Structure.

The purplish color of java plum fruit generally indicates the bond between metals and anthocyanin. Research has proven that the bond between $\mathrm{Fe}$ and anthocyanin create the purple color of tulips $\mathrm{s}^{35}$. However, the formation of a complex compound from Fe and anthocyanin will be more convincing if it is based on the results of XRF, LCMS, FTIR and Crystal analysis. Spectra FTIR showed that there are bioinorganic metal anthocyanin complex compounds (MAC) which can be formed from $\mathrm{Fe}$ and anthocyanins. Anthocyanin easily chelates Fe to form a crystal.

\section{Scavenging Activity and Electron Spin Resonance Measurement of Paramagnetic Properties and DPPH Radical}

The ESR spectra of the java plum (S. cumini) fruit was shown in Fig.-6. Signal originated from $\mathrm{Mn}^{3+}$ of a transition metal with a $d$-orbital was used as unpaired electron reference. ${ }^{23}$ The ESR spectra of Java plum (S. cumini) fruit performed paramagnetic properties because there was an interaction between one or more unpaired electrons of transition metals and organic molecules creating a crystalline MAC compound. This finding was in accordance with the previous study. The researchers reported that the adding metal to quercetin, catechin, and taxifolin solutions would produce unpaired electron at a very low concentration detected by electron paramagnetic resonance (EPR). ${ }^{36}$ It was assumed that the paramagnetic characteristics of Java plum $S$. cumini fruit were originated from unpaired electrons. The electrons of transition metal ion localized in a $d$-orbital such as $\mathrm{Fe}, \mathrm{Cu}$, and $\mathrm{Ni}$ are responsible for the paramagnetic of ESR signal. ${ }^{37,38}$

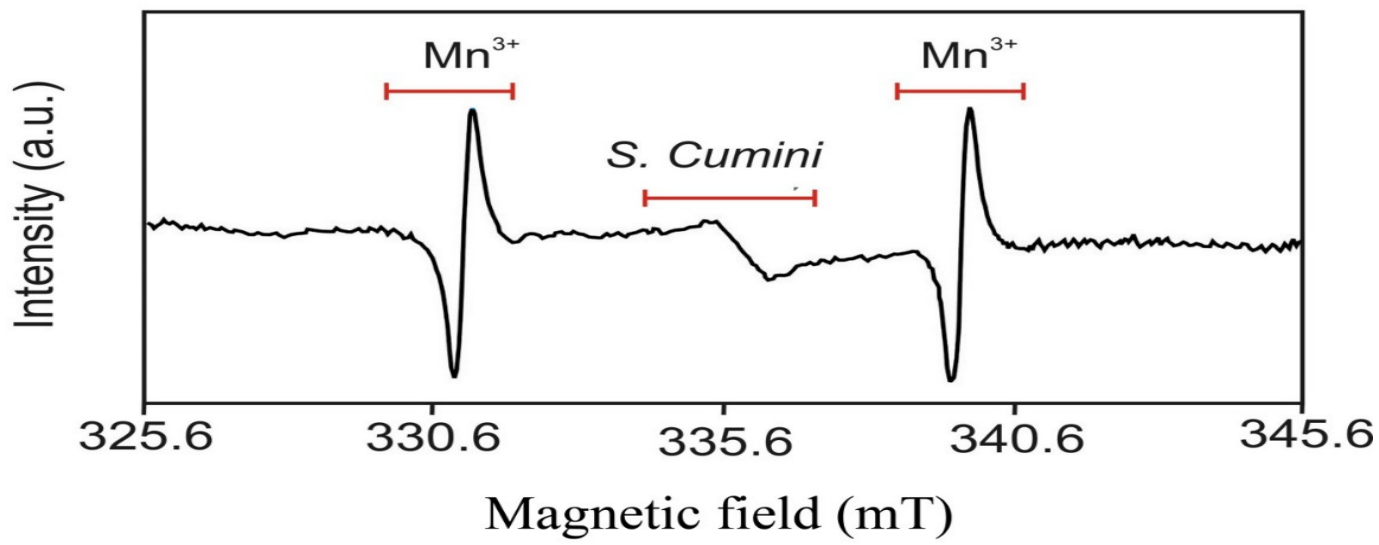

Fig.-6: ESR Signal Showed Paramagnetic Properties of S. cumini Fruit 
RASĀYAN J. Chem.

Vol. 11 | No. 3 |1193 - 1203 | July - September | 2018

The activity of Java plum (S. cumini) fruit against DPPH radical was demonstrated in Fig.-7. The ESR spectrum has proven that fruit containing MAC has an ability to reduce the intensity of free radical DPPH. The $\mathrm{g}$ factor value of DPPH was 2.0063, and $\mathrm{g}$ factor value of fruit and DPPH was 2.0035.The magnetic resonance occurred when magnetic spins of the atoms and unpaired electrons absorb certain frequency and experienced alternating magnetic field with the same frequency as the natural system frequency. Every species of free radicals or unpaired electron had a g-factor value.

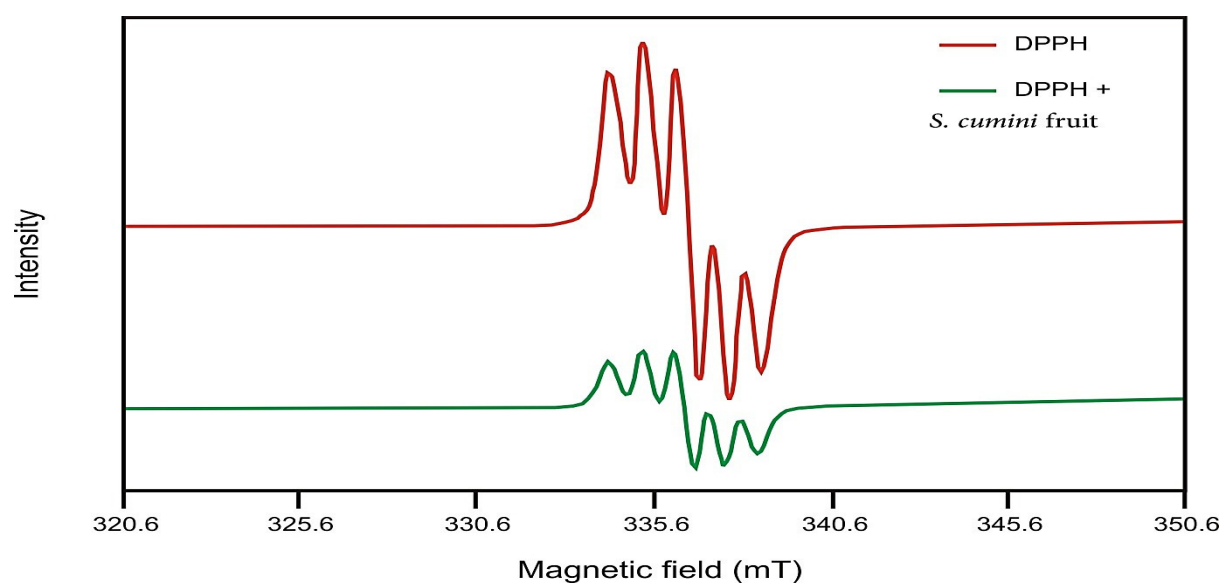

Fig.-7: ESR Signal of S. cumini Fruit Scavenging Activity Against DPPH Radical

The antioxidant activity of anthocyanin or polyphenol donates hydrogen atom from the hydroxyl group to the free radical with the formation of a less reactive flavonoid phenoxy radical. The flavonoid phenoxy radical subsequently undergoes delocalization-unpaired electron, to the aromatic core from $\mathrm{B}$ ring to $\mathrm{C} 2-$ C3 double bond conjugated with a 4-keto group. It can react forward to form unreactive compounds by radical-radical termination. However, the radical scavenger activity of MAC containing anthocyanin behaves like hemes with four pyrrole rings of hemoglobin. Each pyrrole binds to the one of nitrogen porphyrin atom with $\mathrm{Fe}^{2+}$ ion as the center of the atom. The stages of radical scavenger activity of heme on hemoglobin ${ }^{1}$ are as follows: hemoglobin-containing protein binds oxygen on the heme iron when the iron is in the ferrous $\left(\mathrm{Fe}^{2+}\right)$ oxidation state. The replacement of any protein remains as electron transferring. However, molecular oxygen is an oxidizing agent and can promote oxidation of the ferrous iron to the ferric form $\left(\mathrm{Fe}^{3+}\right)$. The conversion of molecular oxygen to superoxide $\left(\mathrm{O}_{2}^{-}\right)$is results from auto-oxidation, as observed $^{1}$ at eqn (1) :

$$
\mathrm{P}-\mathrm{Fe}^{2+}-\mathrm{O}_{2} \rightarrow \mathrm{P}-\mathrm{Fe}^{3+}+\mathrm{O}_{2}^{-}
$$

The hydrogen peroxide is produced either from the dismutation of superoxide or from ferrous heme protein autoxidation which can also oxidize the ferrous protein. The hydrogen peroxide, which acts as, two electrons acceptor generates the ferryl oxidation state of heme protein, as observed at eqn (2):

$$
\mathrm{P}-\mathrm{Fe}^{2+}+\mathrm{H}_{2} \mathrm{O}_{2} \rightarrow \mathrm{P}-\mathrm{Fe}^{4+}=\mathrm{O}_{2}^{-}+\mathrm{H}_{2} \mathrm{O}
$$

The ferryl form decays, either through a disproportionation reaction with ferrous heme, as observed at eqn (3) or through auto-reduction, to construct ferric heme:

$$
\mathrm{P}-\mathrm{Fe}^{4+}=\mathrm{O}_{2}^{-}+\mathrm{P}-\mathrm{Fe}^{2+}+2 \mathrm{H}^{+} \rightarrow 2 \mathrm{P}-\mathrm{Fe}^{3+}+\mathrm{H}_{2} \mathrm{O}
$$

The result of ferric in heme now preferentially reacts with the remaining peroxide, as observed at eqn (4), as:

$$
\mathrm{P}-\mathrm{Fe}^{3+}+\mathrm{H}_{2} \mathrm{O}_{2} \rightarrow \mathrm{P} \bullet-\mathrm{Fe}^{4}=\mathrm{O}_{2}^{-}+\mathrm{H}_{2} \mathrm{O}
$$

The second electron comes from the oxidization of protein since the ferryl heme formation needs one electron to be removed from ferric heme, and $\mathrm{H}_{2} \mathrm{O}_{2}$ needs two electrons to be reduced from the water. The activity of reducing free radicals was performed by flavonoid or anthocyanin metal complex compound and 
resembled the one found inside hemoglobin complex compound which used $\mathrm{Fe}$ as the center. The hemoglobin would not become radicals, but its magnetic field properties were changed from paramagnetic into diamagnetic or vice versa as one of the electrons was released or attached to the metals ${ }^{39}$. This process occurred because the free radicals sought electrons pairs. It was indicated by changes were $\mathrm{Fe}^{2+}$ is oxidized to $\mathrm{Fe}^{3+}$ or the other way around, from $\mathrm{Fe}^{3+}$ to $\mathrm{Fe}^{2+}$. The paramagnetic property of MAC is the result of metals existence ${ }^{36}$ which configure a crystal. This crystal has a paramagnetic property strongly related to its function as a free radical scavenger. Besides $\mathrm{Fe}$, another research finding has found that $\mathrm{Cu}^{2+}$ can also form a complex compound with quercetin, morin, and primuletin which could serve as a free radical scavenger. The scavenger activity is significantly higher than of the parent flavonoid ${ }^{40}$. Therefore, it can be said that complex compounds found in java plum also perform free radical scavenger activity which is more effective than their single compounds.

It paramagnetic property is utilized to catch free radicals so that the compounds only change their paramagnetic characteristics to diamagnetic or the other way around when they accept or release electrons ${ }^{39}$. MAC will not become radicals since its properties are changed from paramagnetic into diamagnetic or vice versa as one of the electrons is released. The mechanism can be related to the free radical scavenger activity of MAC which was higher than the parent flavonoid. Java plum $(S$. cumini) fruit was confirmed to have MAC. In addition, its activity was identified as a free radical scavenger. This is thought to be one of the reasons in which metal anthocyanin complexes are effective as a free radical scavenger, similar to indigenous scavenger systems such as heme in hemoglobin, SOD, and catalase where complex porphyrin act as a ligand with transition metal as the central atom.

\section{CONCLUSION}

The java plum ( $S$. cumini ) fruit contains bio-inorganic compounds which occur naturally between anthocyanin and iron (Fe). In this compound, $\mathrm{Fe}$ and cyanidin (anthocyanin) act as the center of atom and ligand, respectively. The ESR pattern showed that fruit could scavenge the intensity of DPPH radical. It means that the fruit can be used as a free radical scavenger. Interestingly, when it receives an electron, it does not generate a new radical as usually occur in a single compound antioxidant. Furthermore, this metal flavonoid complexes has paramagnetic properties associated with its function as a free radical scavenger. The paramagnetic character of metal flavonoid complex compound changes into diamagnetic when losing or gaining electrons.

\section{ACKNOWLEDGMENT}

This research was funded by The Ministry of Research, Technology and Higher Education through a competitive research program of decentralization and national implementation of the agreement assignment to Research Number: 486.66 / UN 14.2 / PNL.01.03.00 / 2016.

\section{REFERENCES}

1. B.J.Reeder, and M.T. Wilson, Curr. Med. Chem., 12, 2741 (2005)

2. A.N.Kokic, D.Blagojevic, and M.B. Spasic, J. Med. Biochem., 29, 189 (2010), DOI: 10.2478/v10011010-0018-7

3. B.Smyk, B.Pliszka, R. Drabent, Food Chem., 107, 1616 (2008), DOI: 10.1016/j.foodchem.2007.10.037

4. M.Elhabiri, C.Carrër, F.Marmolle, H.Traboulsi, Inorganica Chim. Acta., 360, 353 (2007), DOI:10.1016/j.ica.2006.07.110

5. A. Bencini, P.Failli, B.Valtancoli, and D. Bani, Cardiovasc Hematol Agents Med Chem., 8 (3), 128 (2010), DOI: EPub-Abstract-CHA-MC-15 [pii]

6. V.K. Bajpai, A.Sharma, S.C. Kang, and K.H. Baek, Asian Pac. J. Trop. Biomed.,7, 9(2014), DOI: 10.1016/S1995-7645(13)60183-2

7. H .N. Thanh, H.P.T, Minh, T.A. Le, H.D.T. Ly, T. N. Huu, L.V. Duc, T. D. Kim, and T. B. Thanh, Asian Pac. J. Trop. Biomed., 5 (9), 761 (2015), DOI:10.1016/j.apjtb.2015.07.007

8. M.Valko, D.Leibfritz, J.Moncol, M.T.D.Cronin, M.Mazur, and J. Telser, Int J Biochem Cell., 39, 44 (2007), DOI: 10.1016/j.biocel.2006.07.001

9. F.S. Pala, and K. Tabakcioglu, Advances in Molecular Biology, 1, 63 (2007) 
RASĀYAN J. Chem.

Vol. 11 | No. 3 |1193 - 1203 | July - September | 2018

10. V.A. Kostyuk, A.I.Potapovich, E.N.Strigunova, and T.V.Kostyuk, Arch Biochem Biophys., 428, 204 (2004), DOI: 10.1016/j.abb.2004.06.008

11. A. Pȩkal, M.Biesaga, and K. Pyrzynska, Biometals, 24 (1), 41 (2011), DOI : 10.1007/s10534-010-93727

12. M. Zulfajiri, and Muttakin, Rasayan J. Chem., 11 (1), 135 (2018), DOI:10.7324/RJC.2018.1111983

13. Y.Tanaka, N.Sasaki, and A. Ohmiya, Plant J., 54, 733 (2008), DOI:10.1111/j.1365313X.2008.03447.X

14. S. A. Bittar, N. Mora, M. Loonis, and O. Dangles, Molecules, 19, 709(2014), DOI: 10.3390/molecules191220709

15. F.A. Brito, L.A.Lima, M.F.S.Ramos, M.J. Nakamura, S.C.C.Machado, A.C.Siani, M.G.M.O.Henriques, and A.L.F.Sampaio, Braz. J. Med. Biol. Res., 40, 105 (2007), DOI:10.1590/S0100-879X2007000100014.

16. A.A.Mohamed, S.I. Ali, and F.K. El-Baz., PLoS One, 8(4), 1 (2013), DOI:10.1371/journal.pone.0060269.

17. S. Sandhya, S. Pathak, G. Gupta, S.K.Sharma, L.Singh, R. K.Sharma, A.Mishra, and K. Dua, Biomed Pharmacother., 89, 447 (2017), DOI: 10.1016/j.biopha.2017.02.048

18. Z.Spáčil, L.Nováková, and P. Solich, Food Chem., 123, $535 \quad$ (2010), DOI:10.1016/j.foodchem.2010.04.048

19. B. Wang, J.He, C.Duan, X. Yu, L. Zhu, Z. Xie, C. Zhang, W. Xu, and S. Wang, Scientia Horticulturae, 137, 20 (2012), DOI: 10.1016/j.scienta.2011.10.006.

20. Y.Yoshimura, N. Zaima, T.Moriyama, and Y. Kawamura, PLoS One, 7, (2012), DOI: 10.1371/journal.pone.0031285.

21. A.F.Faria, C. Marcella, and Z. Adriana , Food Chem., 126, 1571 (2011), DOI:10.1016/j.foodchem.2010.12.007

22. X. Keyong, B. Liu, Y. Ma, J.Du, G.LH.Gao, Y. Zhang, Z. Ning, Molecules, 14, 486 (2009), DOI: 10.3390/molecules14093486

23. I. Yusuke, T. Hirasawa, Y. Maruyama, Y. Ishii, R. Ito, K. Saito, T. Umemura, A. Nishikawa, and H. Nakazawa Toxicology in Vitro, 25,1320 (2011), DOI: 10.1016/j.tiv.2011.04.024

24. D. Amic, D. Beslo, and N. Trinajstic, Croat. Chem. Acta, 76 (1), 2058 (2003), DOI:10.1016/j.phytochem.2006.07.002

25. A.M.S.Azima, A.Noriham, and M.Nurhuda, International Journal of Bioscience, Biochemistry and Bioinformatics, 3 (4), 314 (2013), DOI:10.7763/IJBBB.2013.V3.221.

26. Y.Liu, and M. Guo, Molecules, 20 (5), 8583 (2015), DOI: 10.3390/molecules20058583

27. M. Rajendran, R. Ravichandran, and D. Devapiriam, International Journal of Computer Application, 50, 30 (2012)

28. P. Mladěnka, K. MacÁková, T. Filipský, L.Zatloukalová, L.Jahodář, P. Bovicelli, I.P. Silvestri, R.Hrdina, L. Saso, Journal of Inorganic Biochemistry, 105, 693 (2011), DOI: 10.1016/j.jinorgbio.2011.02.003

29. F.A.Miller, and C.H. Wilkins, Anal. Chem., 24,1253(1952)

30. S.Venkateswarlu, B.N.Kumar, C.H. Prasad, P.Venkateswarlu, N.V. V. Jyothi, Physica B: Physics of Condensed Matter., 449, 67 (2014), DOI: 10.1016/j.physb.2014.04.031

31. S. C.Liliana, P.V.M.Diana, and A.A. Alfredo, African Journal of Biotechnology, 14 (6), 442 (2015), DOI: 10.5897/AJB2014.14189

32. P.D. Gurak, L. Maria, C. Cabral, M.H. Rocha-leão, Braz. Arch. Biol. Technol., 56(6), 1011(2013).

33. M.A. Meyers, P. Chen, and A.Y. Lin, Progress in Materials Science, 53, 1 (2008), DOI:10.1016/j.pmatsci.2007.05.002.

34. J.Wei, Y.Liang, Y.Hu, B. Kong, J.Zhang, Q.Gu, Y.Tong, X.Wang, S.P.Jiang, and H. Wang, Angewandte Chemie - International Edition, 55 (40), 12470 (2016), DOI: 10.1002/anie.201606327

35. K. Momonoi, K.Yoshida, S.Mano, K.Takahashi, C.Nakamori, K.Shoji, A.Nitta, and M. Nishimura, Plant J., 59 (3), 437 (2009), DOI: 10.1111/j.1365-313X.2009.03879.x 
36. G.L. Nest, O. Caille, M. Woudstra, S.Roche, B. Burlat, V.Belle, B. Guigliarelli, and D. Lexa, Inorganica Chimica Acta, 357 (7), 2027 (2004), DOI:10.1016/j.ica.2003.11.046

37. B.N. Mondal, A. Mallick, D.N.Nath, and P.P. Chattopadhyay, Metallurgical and Materials Transactions A: Physical Metallurgy and Materials Science, 42 (2), 517 (2011), DOI: 10.1007/s11661010-0432-y

38. M. Ehasanulla, K. Srikanth, A.Veerabhadra Rao and K. A. Emmanuel, Rasayan J. Chem., 4 (2), 343 (2011).

39. K.L. Bren, R.Eisenberg, and H.B. Gray, Proceedings of the National Academy of Sciences, 112 (43), 13123 (2015), DOI: 10.1073/pnas.1515704112

40. Jabeen, E.; Janjua, N.K.; Ahmed, S.; Murtaza, I.; Ali, T.; Hameed, S. Spectrochimica Acta - Part A: Molecular and Biomolecular Spectroscopy.,171, 432 (2017), DOI: 10.1016/j.saa.2016.08.035

[RJC-3047/2018] 